International Review of Research in Open and Distributed Learning

Volume 20, Number 1

February - 2019

\title{
The PERLA Framework: Blending Personalization and Learning Analytics
}

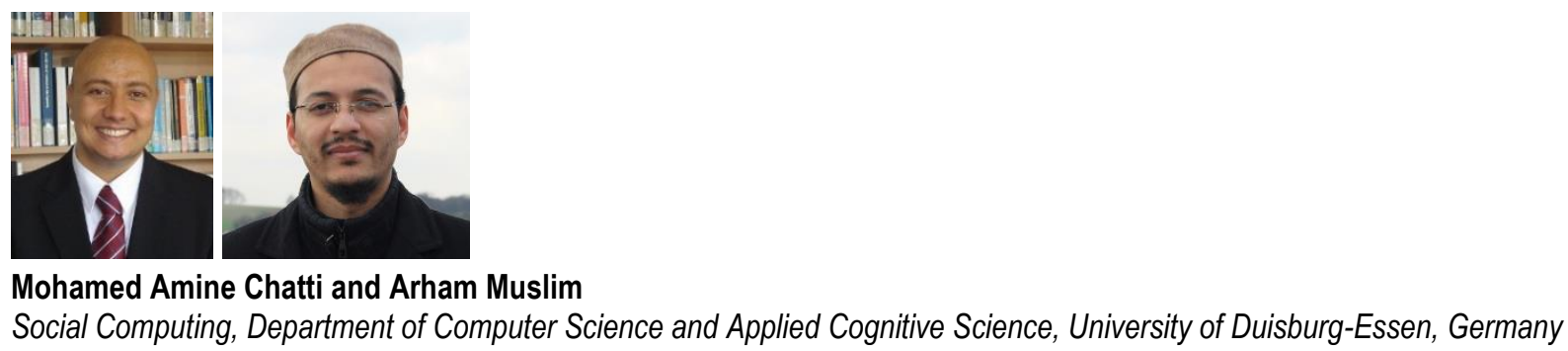

\begin{abstract}
Personalization is crucial for achieving smart learning environments in different lifelong learning contexts. There is a need to shift from one-size-fits-all systems to personalized learning environments that give control to the learners. Recently, learning analytics (LA) is opening up new opportunities for promoting personalization by providing insights and understanding into how learners learn and supporting customized learning experiences that meet their goals and needs. This paper discusses the Personalization and Learning Analytics (PERLA) framework which represents the convergence of personalization and learning analytics and provides a theoretical foundation for effective analytics-enhanced personalized learning. The main aim of the PERLA framework is to guide the systematic design and development of effective indicators for personalized learning.
\end{abstract}

Keywords: Personalization, self-regulated learning, human-centered learning analytics, learning analytics reference model, goal-oriented learning analytics 


\section{Introduction}

The technology-enhanced learning (TEL) landscape is changing. Learning technologies have moved away from only institutionally managed learning systems to learning environments mediated by personal and social tools. In these environments, the challenge is to adopt personalized learning models that engage learners and give them control over the learning experience (Chatti, 2010).

Personalization is a key issue in different lifelong learning settings. In formal learning, different institutions are developing strategies to put a heavier focus on the learner. In informal learning, new trends have emerged over the last years, such as personal learning environments (PLEs), massive open online courses (MOOCs), and open educational resources (OER), where the learners are in control of their own development and learning. In professional learning, there is an increasing interest in the "Workplace 4.o." It cannot be predicted what the workplace of the future will look like, but there is a wide agreement among researchers and practitioners that the learning in the new workplace is personalized and seamlessly integrated into the work process. One of the often cited theoretical models that stresses the great importance of personalized learning at the workplace is the 70-20-10 model, in which $10 \%$ of learning at the workplace is formal through seminars, workshops, and e-learning courses; 20\% is social through collaboration, coaching, and mentoring activities; and 70\% is represented by personalized learning during daily work (Lombardo \& Eichinger, 1996).

To support personalized learning, there is a crucial need for smart learning environments to help learners achieve their learning goals by providing mechanisms that foster awareness, recommendation, selfreflection, assessment, feedback, and motivation. In this perspective, learning analytics (LA) can play an important role by analyzing data collected from various learning environments, supporting customized activities that meet the different learners' needs and goals, as well as providing insights and understanding into how learners perform in these environments and how to best support this process.

There is an increased interest in the application of LA to promote personalized learning. For instance, Roll and Winne (2015) point out that LA offers exciting opportunities for analyzing and supporting personalized learning. According to the authors, LA can provide affordances and interventions for learners to more productively regulate their learning. Marzouk et al. (2016) state that LA, which inform learners about learning activities and respect motivational features of learning, can promote productive personalized learning. Nussbaumer, Hillemann, Gütl, and Albert (2015) also note that LA can provide personalized scaffolds that assist learners in a self-regulated manner. Winne and Baker (2013) posit that educational data mining (EDM) - a research field closely related to LA-can play a significant role advancing research on motivation, metacognition, and self-regulated learning. Further, a variety of LA dashboards and indicators were proposed to support different crucial personalized learning processes, such as awareness, self-reflection feedback, and motivation (Verbert et al., 2014; Gašević, Dawson, \& Siemens, 2015; Bodily et al., 2018). However, while a range of theories and models for personalized learning have been proposed, there remain important gaps in the theory from which to conduct structured research on analyticsenhanced personalized learning. Particularly, there is a lack of theoretically sound frameworks to guide the systematic design and development of LA indicators to scaffold personalized learning. 
Our vision is to blend personalization and LA to design and implement smart learning environments capable to continuously analyze and support the performance of learners, and offer them learning experiences in context. The theme and guiding focus for this work is: How can LA support personalization in different lifelong learning settings (i.e., formal, informal, professional learning) in terms of awareness, recommendation, self-reflection, assessment, feedback, and motivation? To answer this question, we focus on the middle space between personalization and LA through the discussion of the Personalization and Learning Analytics (PERLA) framework, as a learner-centered, analytics-driven conceptual framework that (1) presents crucial requirements to achieve effective analytics-enhanced personalized learning and (2) provides a guideline for designing and developing effective indicators for personalized learning.

\section{Personalization}

One of the core issues in TEL is the personalization of the learning experience (Chatti 2010). There is a crucial need to develop smart learning environments that put the learners at the center and give them more autonomy and control over the learning experience. These environments should help learners decide on and continuously shape their activities to achieve their individual goals. It is important to mention that personalization is different from adaptation. Adaptation is system-driven; the system decides what to do next. Personalization is learner-driven; the system only helps learners decide what to do next. In the following, we present the theoretical background of personalized learning, based on different theories and models.

Chatti (2010) discusses the Learning as a Network (LaaN) theory, as a learner-centered theoretical framework for understanding personalized learning. LaaN draws together some of the concepts behind complexity theory, connectivism, and double-loop learning. The author stresses that personalized learning is a complex activity that must be the product of self-organization. He further points out that connectivism misses some of the double-loop learning concepts, which are crucial for learning, such as learning from failures, reflection, and inquiry. On the other hand, double-loop learning does not recognize the power of connections and networks. According to the author, the LaaN theory starts from the learner and views learning as the continuous creation of a personal knowledge network (PKN), which is a unique repertoire of (a) tacit and explicit knowledge nodes (i.e., people and information) at the external level; and (b) one's theories-in-use at the conceptual/internal level. Theories-in-use can be seen as mental models of ourselves, others, and the environments with which we interact, formed through learning, experience, and culture. These models serve as guides to help achieve our goals (Norman, 2013). In LaaN, the result of learning is a restructuring of one's PKN, that is, an extension of one's external network with new knowledge nodes (external level) and a reframing of one's theories-in-use (conceptual/internal level).

Personalized learning requires self-organization (self-regulation). Self-regulated learning (SRL) is one of the most important areas of research within educational psychology over the last two decades. It includes the cognitive, metacognitive, behavioral, motivational, and emotional/affective aspects of learning (Panadero, 2017). SRL is generally defined as "an active, constructive process whereby learners set goals for their learning and then attempt to monitor, regulate, and control their cognition, motivation, and behavior, guided and constrained by their goals and the contextual features in the environment" (Pintrich, 
2000, p. 453). Panadero (2017) provides an excellent analysis and comparison of different SRL models. Next, we outline the five most influential SRL models, with a focus on the phases and processes included in these models.

Zimmerman's (2000) SRL model is organized in three cyclical phases: forethought, performance, and selfreflection. In the forethought phase, the learners analyze the task, set goals, and plan how to reach them. In the performance phase, the learners actually execute the task. And, in the self-reflection phase, the learners evaluate how they have performed the task, which can positively or negatively influence their later performances (Zimmerman, 2000; Zimmerman \& Moylan, 2009; Zimmerman, 2013).

Pintrich's (2000) SRL model emphasizes the role of motivation in SRL. It encompasses four phases: (a) forethought, planning, and activation; (b) monitoring; (c) control; and (d) reaction and reflection. Each of them has four different areas for regulation: cognition, motivation/affect, behavior, and context. The combination of those phases and areas offers a comprehensive picture on different SRL processes (Pintrich, 2000).

Winne and Hadwin's (1998) SRL model stresses the cognitive and metacognitive aspects of SRL and explains how learners' cognitive processing operates while planning, performing, and evaluating a task. The model builds on the COPES (i.e., conditions, operations, products, evaluation, and standards) to describe how learners use tactics and strategies to perform tasks and constantly monitor their activities against standards, based on four recursive linked phases: (a) definition of task: the learners generate an understanding of the task to be performed and the factors that may affect that task; (b) goals and plan(s): the learners set goals and plans for reaching them; (c) studying tactics: the strategies and actions needed to reach the goals; and (d) adaptations: long term changes in the learner's beliefs, motivations, and strategies for the future (Winne \& Hadwin, 1998; Winne, 2011).

Boekaerts' (1992) first SRL model, namely, the Adaptable Learning Model, describes the dynamic aspects of SRL based on two parallel processing modes: (a) a mastery or learning mode, and (b) a coping or wellbeing mode. The appraisals made by the learners determine which mode they will activate (Boekaerts, 1992, 1996; Boekaerts \& Niemivirta, 2000). The Adaptable Learning Model evolved later into the Dual Processing Self-Regulation model, which adds the top-down and bottom-up concepts (Boekaerts \& Cascallar, 2006; Boekaerts, 2011). According to Boekaerts (2011), there are two goal pathways for self-regulation. The first is the mastery/growth pathway (or what she called top-down) that the learners activate if the task goal is congruent with their goals and needs. The second is the well-being pathway (or bottom-up) that the learners activate if they experience a mismatch between the task goals and their personal goals, and to protect their ego from being damaged. In Boekaerts' Dual Processing model, positive and negative emotions play a key role to determine which goal pathway the learners will activate.

Efklides (2011) proposes the Metacognitive and Affective Model of Self-Regulated Learning (MASRL) with an emphasis on the metacognitive, motivational, and affective aspects of SRL. In the MASRL, there are two levels. First, the Person level (also called macrolevel), represents the general learners' characteristics, such as cognitive ability, motivation, self-concept, and affect. Efklides considers the Person level to be top-down because goals are set in accordance with the learner's characteristics and the task is guided based on those personal goals. Second, the Task x Person level (microlevel) where the interaction between the task and the 
learner's characteristics takes place. This level is bottom-up, because the task directs and regulates the learner's actions.

The personalized learning models outlined above address different aspects of learning. However, all of them assert the goal-driven nature of personalized learning and view personalized learning as a cyclical process, composed of different phases. Although expressed using different labels, all models share three identifiable phases: (a) goal setting (forethought, task analysis, planning, activation of goals, self-motivation); (b) executing (performance, processing); and (c) evaluating (self-reflection, feedback, monitoring, controlling, appraisal, regulating, adapting, reacting; Panadero, 2017). In the next sections, we discuss in detail how the emerging research field of learning analytics can support these phases and thus promote personalized learning.

\section{Learning Analytics}

A large volume of data about learners and learning is being generated. This data is mainly traces that learners leave as they interact with various learning environments. Learning analytics (LA) focuses on the development of methods for analyzing and detecting patterns within this data, and leverages those methods to support the learning experience. Different definitions have been provided for LA. The most commonly cited LA definition which was adopted by the first international conference on learning analytics and knowledge (LAK11) is "the measurement, collection, analysis and reporting of data about learners and their contexts, for purposes of understanding and optimizing learning and the environments in which it occurs" (Siemens \& Gašević, 2012).

\section{The Learning Analytics Reference Model}

Chatti et al. $(2012,2014)$ propose a reference model for LA that provides a systematic overview on LA and fosters a common understanding of the key components of the LA ecosystem, based on four dimensions of the LA reference model, namely:

- What? What kind of data does the system gather, manage, and use for the analysis? This dimension refers to the data used in the LA task. It also refers to the environments and contexts in which learning occurs.

- Why? Why does the system analyze the collected data? There are many objectives in LA according to the particular point of view of the different stakeholders.

- Who? Who is targeted by the analysis? The application of LA can be oriented toward different stakeholders with different perspectives, goals, and expectations from the LA task.

- How? How does the system perform the analysis of the collected data? LA applies different methods to detect interesting patterns hidden in educational data sets.

\section{The Learning Analytics Cycle}

LA is an iterative and cyclical process generally carried out in six major steps (Figure 1). These steps are iterated; that is, they are repeated over and over, with each cycle yielding more effective learning activities: 
- Learning Activities. The LA cycle starts with a concrete learning activity, which is a crucial part for LA (Griffiths Hoel, \& Cooper, 2016). A learning activity can occur in centralized educational systems (e.g., LMS) or in open and networked learning environments (e.g., social media, MOOCs, PLEs).

- Data Collection. LA is a data-driven approach. Collecting data from different learning environments is the foundation of the LA process. Today we have broad access to high-volume data from a variety of sources. The data can come from multiple, fragmented, often heterogeneous, formal, as well as informal, learning channels. It can also come in different formats, distributed across space, time, and media.

- Data Storage and Processing. The collected data then needs to be stored properly. The data can be stored in the platform that generates them (e.g., LMS) or transferred to a data warehouse (e.g., Learning Record Store). The quantity and quality of the data determine the discovery of useful patterns in the data. The data may be heterogeneous with different formats and granularity levels. In this case, a data integration step is required to match data against each other. The data may involve unnecessary attributes, and thus needs to be processed. Data processing may also be required to transform the data into an appropriate format that can be used as input for a particular LA method.

- Analysis. The data can then be analyzed using different analysis methods such as statistics, data mining, and social network analysis to find patterns and generate insights from the data.

- Visualization. The analysis results can then be represented as an indicator in a user-friendly visual form that can help to understand and interpret the results as well to infer from the data conclusions that can improve the learning process.

- Action. Taking actions is the primary aim of the whole LA process. These actions include intervention, self-reflection, goal or strategy adaptation, and planning of new learning activities.

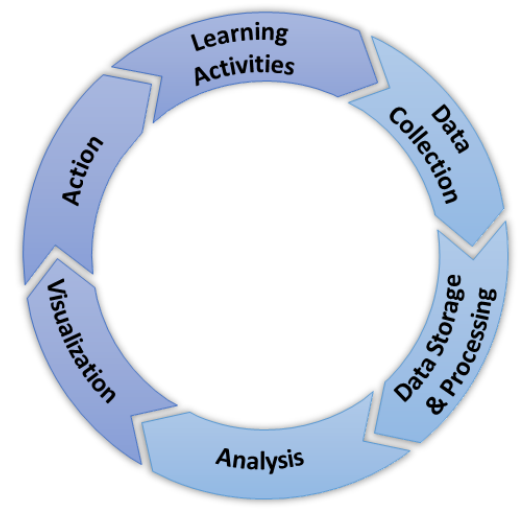

Figure 1. The learning analytics cycle. 


\section{Human-Centered Learning Analytics}

LA aims at optimizing the learning achievement, as well as the learning process. In the ideal case, LA is a continuous movement from data to analysis to action to learning. While several studies have revealed the importance of using and analyzing data, few have highlighted how the move will be made from analyzing the data to optimizing the learning. Consequently, we are still lacking evidence that LA is having any positive impact on learning (Ferguson \& Clow, 2017; Gašević et al., 2015). This hinders the adoption of LA at scale in schools, universities, and workplaces. The solution is human-centered LA (HCLA), an approach that emphasizes the human factors in LA and truly meets the user's needs. User involvement in the design, deployment, and evaluation of LA is a key requirement to serve the needs of different users with diverse goals in an effective way. It is vital to engage the various LA stakeholders (learners, teachers, institutions, researchers, developers, etc.) in the LA process. Especially, the learner should take an active role in the LA process, if LA tools are to serve the intended objective of improving learning.

Adopting a HCLA approach to support personalized learning requires that LA researchers and developers use qualitative studies where they go to the learners, observe their activities, and try to understand what they really need. Thereby, it is important to have a good understanding of the requirements for a successful analytics-enhanced personalized learning system as well as to find the right set of questions to ask in the study in order to generate effective indicators for personalized learning. To get at this, we present and discuss the PERLA framework as a theoretical foundation for effective analytics-enhanced personalized learning.

\section{The PERLA Framework}

The Personalization and Learning Analytics (PERLA) framework (Figure 2) is an HCLA conceptual framework to effectively support personalization in different lifelong learning settings. The main aim of the PERLA framework is to provide LA researchers and developers with a systematic way to design and develop indicators to support personalized learning, by giving answers to the following questions:

1. What are the requirements that need to be addressed in order to design and develop effective indicators for personalized learning? and

2. Which indicators are needed to support personalized learning? 


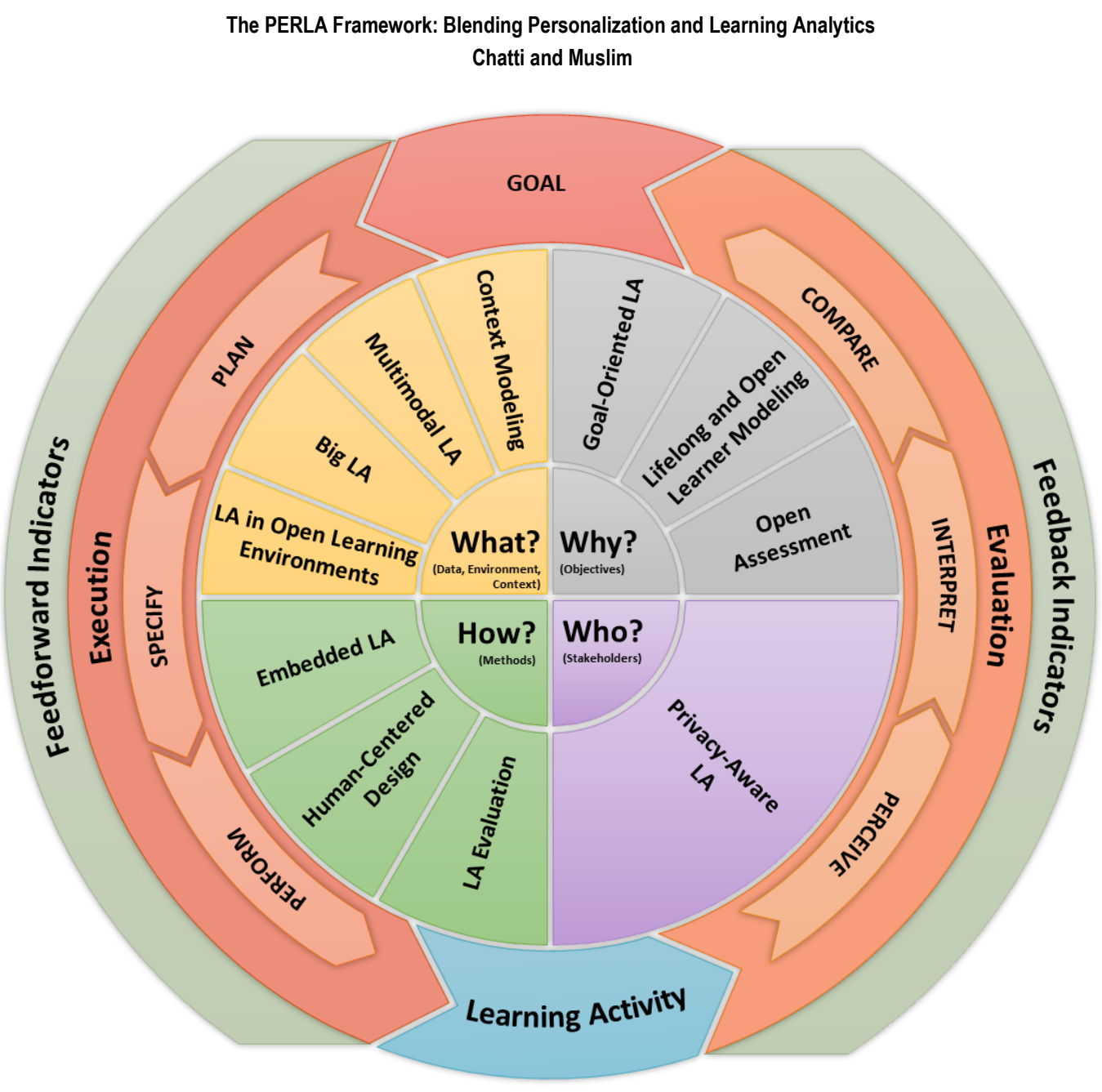

Figure 2. The PERLA framework.

\section{Requirements}

The inner part of the PERLA framework represents the conceptual and technical requirements that need to be addressed in order to design and develop an effective analytics-enhanced personalized learning environment. These requirements are mapped to the four dimensions of the LA reference model. In the following, we discuss these requirements in some detail by taking a learner perspective.

LA in open learning environments. Learning is increasingly taking place in open and networked learning environments (e.g., social media, MOOCs, PLEs). These environments capture and store large data sets from distributed learners' activities that can provide insight into the learning processes. Further, these environments house a wide range of learners with diverse interests and needs. Understanding how learners are engaging with learning materials and peers by analyzing their learning activities is a crucial step towards smart learning environments that best meet the needs of different learners through timely personal feedback. In addition, due to the open nature of the new learning environments, learners are often overwhelmed with the flow of knowledge. LA can help to form the basis for increased awareness and effective recommendation by supporting learners in getting knowledge in context from a wide range of sources. It is important to stress that, as learners' activities are ubiquitous, it 
is crucial to take account of the context in which the data is collected in order to avoid misinterpretations of LA results.

Big LA. A large volume of data-referred to as big data-about learners and learning processes is being generated from learners' activities across various learning environments. Generally, the literature presents a number of fundamental characteristics associated with the notion of big data including volume (amount of data), velocity (speed of data in and out), variety (range of data types and sources), veracity (biases, noise, and abnormality in data generated from various sources and questions of trust and uncertainty associated with the collection, processing, and utilization of data), and value (ability of data in generating useful insights and benefits; Daniel \& Butson, 2014). Following these characteristics, data from learning processes can be characterized as big data (Chatti et al., 2017):

- Volume - A single online learning platform can generate thousands of transactions per learner.

- Velocity - The data that is collected should be processed and analyzed in real time to provide accurate and timely feedback.

- Variety - The data that needs to be analyzed comes from a variety of sources, such as LMS log files, assessment scores, social web, etc.

- Veracity - Quality of data, privacy, and security issues need to be resolved in order to build trust and achieve legitimacy in the LA process.

- Value - The main aim of LA is to harness the educational data to provide insight and improve the learning processes.

Thus, there is a need to leverage big data methods, such as NoSQL databases, stream processing, predictive analytics, and visual analytics to develop a better understanding of the learner activities in open and networked learning environments. To stress, however, that the lack of adoption of LA among learners is not due to technological aspects related to the volume, velocity, and variety of educational data but more to pedagogical ones related to veracity and value. In practice, learners still do not see the added-value of LA. It is thus essential to promote learner-centered LA approaches that see learners as the central part of the LA practice and involve them in all the LA steps. Learner involvement is the key to a wider acceptance and adoption of LA.

Multimodal LA. Multimodal LA goes beyond logged-data gained from the direct interactions between learners and learning management systems by combining them with diverse other multimodal learning activity data, such as audio, video, writing, gestures, postures, facial expressions, gaze, and other biometrics captured via biosensors to assess the learning activities and offer new insights into understanding and optimizing learning activities in both digital and physical world scenarios (Blikstein, 2013; Ochoa, 2017). In particular, multimodal data traces can be useful to gain meaningful insights into personalized learning processes.

Context modeling. Context is crucial to achieve personalized learning. Context can be categorized into two types: extrinsic and intrinsic context (Thüs et al., 2012). The extrinsic context deals 
with the learner's current state of the environment. It may be time, location, relation to other learners, or the current learning activity. Intrinsic context information deals with the inside of a learner, such as the learner's level of attention or the level of motivation. A big challenge to tackle here is context modeling. A context model should reflect a complete picture of the learner's context information. The aim is that the extrinsic and intrinsic context information gathered from different learning channels would be fed into a personal context model, which would build the base for context-aware LA solutions. Different specifications for activity data modeling have been introduced in the LA literature. The most prominent ones to date are the Experience API (xAPI) and IMS Caliper. These data models, however, are event-centered rather than user-centered, which is required to support personalized learning experiences. Moreover, they do not preserve the semantic meaning of the stored events (e.g., the verb-ambiguity problem in xAPI), which could lead to misinterpretations and inaccurate LA results. Further, they do not provide mechanisms to deal with the privacy issue in LA.

Goal-oriented LA. It is important to follow a goal-oriented LA model that tailors the LA task to the learner's goals. There is a need to adopt a learner-in-the-loop LA approach that engages learners in a continuous exploratory and inquiry-based LA process, by supporting them in setting goals, formulating questions, and self-defining the indicators to answer these questions. This would also make the analytics process more transparent, enabling learners to see what kind of data is being used and for which purpose (Muslim et al., 2017).

Lifelong and open learner modeling. Learner modeling is the cornerstone of personalized learning. The six most popular and useful features in learner modeling include the learner's knowledge, interests, goals, background, individual traits, and context (Brusilovsky \& Millan, 2007). The capacity to build a detailed picture of the learner across learning contexts would provide a more personalized learning experience. A big challenge to tackle here is lifelong learner modeling. A lifelong learner model is a store for the collection of learning data about an individual learner. Lifelong learner modeling is the continuous collection of personal data related to a learner. It is an ongoing process of creating and modifying a model of a learner, who tends to acquire new or modify his or her existing knowledge, skills, or preferences continuously over a longer time span (Kay \& Kummerfeld, 2011). In order to achieve appropriate lifelong learner modeling, several issues have to be taken into account, including questions about integration, interoperability, reusability, extensibility, and privacy. Another important concept is open learning modeling based on user interfaces that enable refection, planning, attention, and forgetting, that can be accessed by learners to control, edit, update, and manage their models (Bull \& Kay, 2016). This is important to build trust and improve transparency of LA.

Open assessment. Personalized learning requires new assessment models to recognize and evaluate self-directed and lifelong learning achievements in increasingly open and networked learning environments. Open assessment is an umbrella term for different assessment methods, such as eassessment, self-assessment, peer-assessment, and feedback. It is an agile way of assessment where anyone, anytime, anywhere, can participate towards the assessment goal. Open assessment is an ongoing process across time, locations, and devices where everyone can be assessor and assessee. LA has the potential to support open assessment by giving timely and personalized feedback in context, providing an explanation 
on how and why a feedback was given, validating peer-assessment, and visualizing the learning achievements to support awareness, trigger self-reflection, and promote self-assessment.

Privacy-aware LA. Privacy is a big challenge in LA. This challenge is further amplified when learner data is collected from various sources. It is crucial to build privacy into the LA solutions right from the very beginning. Several frameworks are proposed in the literature with guiding principles for privacyaware LA. These frameworks share the focus on two major principles, namely transparency and learner control over the data. Transparency is vital to drive forward the acceptance of LA and thus should be applied across the complete LA process, without exceptions. This means that at all times, there should be easily accessible and detailed documentation of how is the data collected, who has access to the data, which analytics methods are applied to the data, how long is the data valid and available, the purposes for which the data will be used, under which conditions, and which measures are undertaken to preserve and protect the identity of the learner (Pardo \& Siemens, 2014; Slade \& Prinsloo, 2013). Further, it is crucial to give learners full control over their data by letting them decide on what kind of data is being used for which purpose. This is important to build trust in LA.

LA evaluation. In analytics-enhanced personalized learning scenarios, it is important to investigate user-centered, mixed-method evaluation approaches that combine both quantitative and qualitative evaluation methods. Further, it is crucial to go beyond the usability evaluation of the LA tool to measure its impact on learning. Usability of LA tools is just the tip of the iceberg and is relatively easy to evaluate. The challenge is to investigate how LA could impact personalized learning and how this could be evaluated. Measuring the impact of LA tools is a challenging task, as the process needs long periods of time as well as a lot of effort and active participation from learners with different goals.

Human-centered design. For the development of usable and useful LA tools for personalized learning, it is vital to adopt a human-centered design approach that starts with a good understanding of users and the needs that the design is intended to meet. Human-centered design is the key to learner acceptance of LA solutions. Learners should be actively involved in the design process, not just mere data subjects and recipients of interventions and services (Slade \& Prinsloo, 2013). Moreover, human-centered design principles and guidelines should be taken into account. Important characteristics of good design are discoverability (what actions are possible and where and how to perform them), understanding (what do the system and all the different controls and settings mean), and feedback (immediate and informative information about the impact of the action). Good design also requires good communication, especially from LA tool to learner, indicating for instance what actions are possible and what is happening (Norman, 2013). Appropriate visualizations can make a significant contribution to understanding the large amounts of educational data. Statistical, filtering, and mining tools should be designed in a way that can help learners achieve their analytics goals without the need for having an extensive knowledge of the techniques underlying these tools.

Embedded LA. LA is most effective when it is an integrated part of the learning environment. It is important to embed LA tools into the standard learning toolsets of the learner. Moreover, effective LA tools are those that minimize the time frame between analysis and action. In general, teachers use dashboards to monitor the learning activities in their courses. For learners, however, it is more effective to 
follow an embedded LA approach by implementing small LA applications in context to give useful information and feedback at the right place and time.

\section{Indicators}

The requirements outlined in the previous section need to be taken into consideration when designing and developing indicators for personalized learning. The question that might be raised now is: Which indicators are needed to support personalized learning? It is obvious that in a personalized learning context, the set of required indicators is unpredictable. However, the different phases of the personalized learning process can provide a systematic way to categorize these indicators.

Personalized learning is a cyclical process, composed of three general phases. In his classic book The Design of Everyday Things, Norman (2013) discusses seven stages of action that provide a guideline for developing usable and understandable new products or services, following a human-centered design (HCD) approach. By associating the typical three phase personalized learning process and Norman's seven stages of the action cycle, the personalized learning process can be modeled as a cyclical seven stages activity, as shown in Figure 3 as well as the outer part of the PERLA framework (Figure 2). In detail, there are three major phases to a personalized learning activity: goal setting, executing, and evaluating. The execution phase is further subdivided into three stages that follow from the goal: plan, specify, and perform. The evaluation phase is further broken down into three stages: perceive, interpret, and compare.

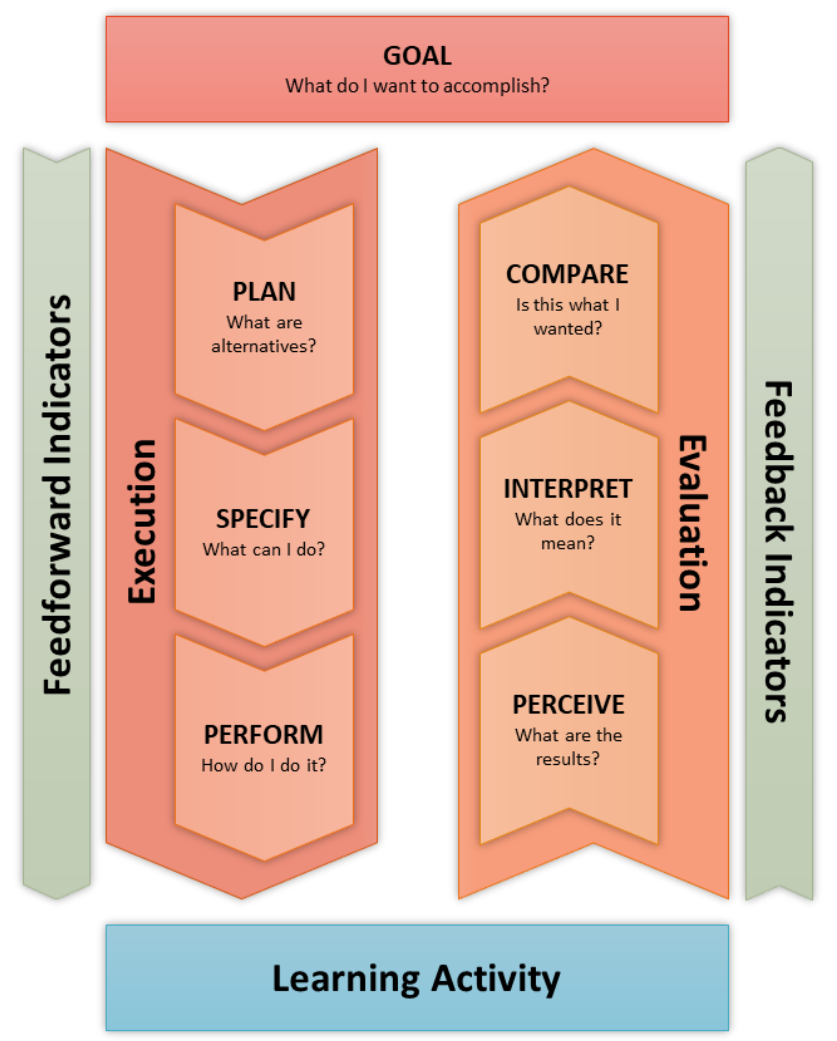

Figure 3. The seven stages of the personalized learning activity cycle. 
The personalized learning activity cycle starts from the top with the learning goal (goal) and then goes through the three stages of execution: planning the possible learning activities to achieve those goals (plan), specify a learning activity path (specify), and perform the learning activity (perform). The cycle then goes through the three stages of evaluation: perceiving the results of the learning activity (perceive), trying to make sense of it (interpret), and comparing the learning outcome with the goal (compare). It is important to stress that most personalized learning activities require multiple feedback loops in which goals lead to subgoals, and the results of one activity are used to trigger further ones.

Each of the seven stages represents a possible question to ask towards a personalized learning activity. The seven-stage personalized learning activity cycle provides a useful tool for guiding the design of indicators for personalized learning. The role of LA is to help learners by conveying the information required to answer the learner's question at each stage of the execution and evaluation phases through appropriate indicators. Indicators that provide information that helps answer questions of execution (the left side of Figure 3) are feedforward indicators. These include indicators for awareness and recommendation. Indicators providing information that aids in answering questions of evaluation (the right side of Figure 3) are feedback indicators. These include indicators for monitoring, self-reflection, assessment, feedback, and motivation. The use of appropriate indicators at each stage enhances the overall personalized learning process. In the following, we summarize the questions related to the stages of the execution and evaluation phases along with the description of the indicators needed to answer these questions:

- Plan (What are alternatives?): Provide information needed to understand how the learning system is supposed to be used as well as what the different features mean.

- Specify (What can I do?): Provide information to help learners decide on the appropriate learning activity path.

- Perform (How do I do it?): Provide information on best strategies in order to perform a task in an effective and efficient way.

- Perceive (What are the results?): Provide information to communicate the results of the performed tasks and the current state of the learning activity.

- Interpret (What does it mean?): Provide information to help learners understand the results and the impact of the learning activity in context.

- Compare (Is this what I wanted?): Provide information about progress towards goals.

Table 1 shows an example of the seven stages of the personalized learning activity cycle in action. 
Table 1

Applying the Seven Stages of the Personalized Learning Activity Cycle to Generate Indicators in a MOOC Scenario

\begin{tabular}{|c|c|c|c|}
\hline & Stages & Indicators & $\begin{array}{l}\text { Indicator } \\
\text { objectives }\end{array}$ \\
\hline & $\begin{array}{l}\text { Goal: Active participation } \\
\text { in the MOOC } \\
\text { - What do I want to } \\
\text { accomplish? }\end{array}$ & - Top 10 contributors in the MOOC. & Motivation \\
\hline \multirow{3}{*}{ 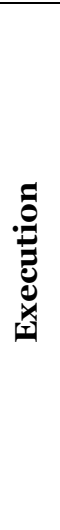 } & $\begin{array}{l}\text { Plan } \\
\text { - What are alternatives? }\end{array}$ & $\begin{array}{l}\text { Overview of activities in the different } \\
\text { collaboration modules of the platform (discussion } \\
\text { forums, peer- reviews, annotations, etc.). }\end{array}$ & Awareness \\
\hline & $\begin{array}{l}\text { Specify } \\
\text { - What can I do? }\end{array}$ & $\begin{array}{l}\text { - Most active threads in discussion forums. } \\
\text { - Most annotated learning resources. } \\
\text { - Most discussed topics. } \\
\text { - Reminder for peer-review deadlines. } \\
\text { - Newsfeed. }\end{array}$ & $\begin{array}{l}\text { Recommendation } \\
\text { Awareness }\end{array}$ \\
\hline & $\begin{array}{l}\text { Perform } \\
\text { - How do I do it? }\end{array}$ & $\begin{array}{l}\text { - Show top rated annotations to be used as } \\
\text { reference. }\end{array}$ & Recommendation \\
\hline \multirow{3}{*}{ 苞 } & $\begin{array}{l}\text { Perceive } \\
\text { - What are the results? }\end{array}$ & $\begin{array}{l}\text { - Statistics on performed collaboration activities } \\
\text { (annotations, peer-reviews, posts in discussion } \\
\text { forums, ratings, etc.). }\end{array}$ & Monitoring \\
\hline & $\begin{array}{l}\text { Interpret } \\
\text { - What does it mean? }\end{array}$ & $\begin{array}{l}\text { - Clustering/classification of participants based on } \\
\text { their activities (number of posts, ratings, peer- } \\
\text { reviews, annotations, etc.). } \\
\text { - Show position in the social network based on the } \\
\text { collaboration activities. }\end{array}$ & $\begin{array}{l}\text { Self-reflection } \\
\text { Feedback } \\
\text { Assessment }\end{array}$ \\
\hline & $\begin{array}{l}\text { Compare } \\
\text { - Is this what I wanted? }\end{array}$ & $\begin{array}{l}\text { - Scale showing contribution status against the } \\
\text { specified goal. }\end{array}$ & Motivation \\
\hline
\end{tabular}

The seven stages of the personalized learning activity cycle provide a guideline for developing effective qualitative user studies attempting to understand what learners really need from LA. Rather than asking learners about their abstract expectations of LA indicators, it is more effective to observe (or if not possible ask about) what they do at each of the seven stages and then co-generate ideas for indicators that can support each stage. These indicators will be useful because they do fit real needs. This is at the heart of human-centered learning analytics.

\section{Conclusion}

In technology-enhanced learning (TEL) research, there has been a continuous interest in smart learning environments that start from the learner and provide him or her a personalized learning experience in 
context. In this paper, we stressed that the emerging research field of learning analytics (LA) can be a valuable tool to support personalized learning in terms of awareness, recommendation, self-reflection, assessment, feedback, and motivation. We further demonstrated that LA can be grounded in theoretical research on personalized learning and presented the PERLA framework that aims at blending personalization and LA toward an effective analytics-enhanced personalized learning experience. The PERLA framework is an umbrella to anchor crucial requirements that affect personalized learning, offering, at the same time, a comprehensive framework that provides LA researchers and developers with a systematic way to design and develop indicators to support personalized learning. This work makes a significant contribution to TEL research because it lays down a theoretical foundation that can guide the design of analytics-driven smart learning environments in different lifelong learning contexts and allow future empirical works to be placed within a common framework. 


\section{References}

Blikstein, P. (2013). Multimodal learning analytics. In Proceedings of the Third International Conference on Learning Analytics and Knowledge (LAK 13), 102-106, New York, NY, USA. ACM.

Boekaerts, M. (1992). The adaptable learning process: Initiating and maintaining behavioural change. Applied Psychology, 41(4), 377-397.

Boekaerts, M. (1996). Coping with stress in childhood and adolescence. In M. Zeidner \& N. S. Endler (Eds.), Handbook of coping: Theories, research, application (pp. 452-484). New York, NY: Wiley.

Boekaerts, M. (2011). Emotions, emotion regulation, and self-regulation of learning. In B. J. Zimmerman and D. H. Schunk (Eds.), Handbook of self-regulation of learning and performance (pp. 408425). New York, NY: Routledge.

Boekaerts, M., \& Cascallar, E. (2006). How far have we moved toward the integration of theory and practice in self-regulation? Educational Psychology Review, 18(3), 199-210. doi: 10.1007/s10648-006-9013-4

Brusilovsky, P., \& Millan, E. (2007). User models for adaptive hypermedia and adaptive educational systems. In P. Brusilovsky, A. Kobsa, \& W. Nejdl (Eds.), The adaptive web (pp. 3-53). Berlin Heidelberg: Springer.

Boekaerts, M., \& Niemivirta, M. (2000). Self-regulated learning: Finding a balance between learning goals and ego-protective goals. In M. Boekaerts, P. R. Pintrich, \& M. Zeidner (Eds.), Handbook of selfregulation (pp. 417-451). San Diego, CA: Academic Press. doi: 10.1016/b978-0121098902/50042-1

Bull, S., \& Kay, J. (2016). SMILI): A framework for interfaces to learning data in open learner models, learning analytics and related fields. International Journal of Artificial Intelligence in Education, 26(1), 293-331.

Chatti, M. A. (2010). Personalization in technology enhanced learning: A social software perspective. Aachen: Shaker Verlag.

Chatti, M. A., Dyckhoff, A. L., Schroeder, U., \& Thüs, H. (2012). A reference model for learning analytics. International Journal of Technology Enhanced Learning (IJTEL), 4(5-6), 318-331.

Chatti, M. A., Lukarov, V., Thüs, H., Muslim, A., Yousef, A. M. F., Wahid, U. ... Schroeder, U. (2014). Learning analytics: Challenges and future research directions. E-learning and Education, 1O(1).

Chatti, M. A., Muslim, A., \& Schroeder, U. (2017). Toward an open learning analytics ecosystem. In Kei Daniel B. (Eds.), Big data and learning analytics in higher education (pp. 195-219). Springer. 
Daniel, B., \& Butson, R. (2014). Foundations of big data and analytics in higher education. In Proceedings of the 9th International Conference on Analytics Driven Solutions (ICAS 2014). Retrieved from http://archive.engineering.nyu.edu/files/ICAS2014-Proceedings-Publication.pdf $\#$ page $=51$

Efklides, A. (2011). Interactions of metacognition with motivation and affect in self-regulated learning: The MASRL model. Educational Psychologist, 46(1), 6-25.

Ferguson, R., \& Clow, D. (2017). Where is the evidence? A call to action for learning analytics. In Proceedings of the Seventh International Learning Analytics \& Knowledge Conference, 56-65. ACM, New York, USA.

Gašević, D., Dawson, S., \& Siemens, G. (2015). Let's not forget: Learning analytics are about learning. TechTrends, 59(1), 64-71.

Griffiths, D., Hoel, T., \& Cooper, A. (2016). Learning analytics interoperability: Requirements, specifications, and adoption. Learning Analytics Community Exchange (LACE) Deliverable D7.4. Retrieved from http://www.laceproject.eu/wp-content/uploads/2016/01/LACE D7-4.pdf

Lombardo, M. M., \& Eichinger, R. W. (1996). The career architect development planner (1st ed.). Minneapolis: Lominger.

Kay, J., \& Kummerfeld, B. (2011). Lifelong learner modeling. In P. J. Durlach, \& A.M. Lesgold (Eds.), Adaptive technologies for training and education (pp. 140-164). Cambridge: Cambridge University Press.

Marzouk, Z., Rakovic, M., Liaqat, A., Vytasek, J., Samadi, D., Stewart-Alonso, J. ... Nesbit, J. C. (2016). What if learning analytics were based on learning science? Australasian Journal of Educational Technology, 32(6), 1-18.

Muslim, A., Chatti, M., Mughal, M., \& Schroeder, U. (2017). The Goal - Question - Indicator approach for personalized learning analytics. In Proceedings of the 9th International Conference on Computer Supported Education (CSEDU 2017). DOI: 10.5220/0006319803710378

Norman, D. (2013). The design of everyday things. New York, NY: Basic Books.

Nussbaumer, A., Hillemann, E. C., Gütl, C., \& Albert, D. (2015). A competence-based service for supporting self-regulated learning in virtual environments. Journal of Learning Analytics, 2(1), 101-133.

Ochoa, X. (2017). Multimodal learning analytics. In C. Lang, G. Siemens, A. Wise, \& D. Gaševic (Eds.), Handbook of learning analytics (pp. 129-141). Alberta, Canada: Society for Learning Analytics Research (SoLAR). doi: 10.18608/hla17

Panadero, E. (2017). A review of self-regulated learning: Six models and four directions for research. Frontiers in Psychology, 8(422). doi: 10.3389/fpsyg.2017.00422 
Pardo, A., \& Siemens, G. (2014). Ethical and privacy principles for learning analytics. British Journal of Educational Technology, 45(3), 438-450.

Pintrich, P. R. (2000). The role of goal orientation in self-regulated learning. In M. Boekaerts, P. R. Pintrich, \& M. Zeidner (Eds.), Handbook of self-regulation (pp. 452-502). San Diego, CA: Academic Press.

Roll, I., \& Winne, P. H. (2015). Understanding, evaluating, and supporting self-regulated learning using learning analytics. Journal of Learning Analytics, 2(1), 7-12.

Siemens, G., \& Gašević, D. (2012). Special issue on learning and knowledge analytics. Educational Technology \& Society, 15(3), 1-163.

Slade, S., \& Prinsloo, P. (2013). Learning analytics: Ethical issues and dilemmas. American Behavioral Scientist, 57(10), 1510-1529.

Thüs, H., Chatti, M. A., Yalcin, E., Pallasch, C. Kyryliuk, B., Mageramov, T., \& Schroeder, U. (2012). Mobile learning in context. International Journal of Technology Enhanced Learning, 4(5-6), 332-344.

Verbert, K., Govaerts, S., Duval, E., Santos, J. L., Van Assche, F., Parra, G., \& Klerkx, J. (2014). Learning dashboards: An overview and future research opportunities. Personal and Ubiquitous Computing, 18 (6), 1499-1514.

Winne, P. H. (2011). A cognitive and metacognitive analysis of self-regulated learning. In B. J. Zimmerman, \& D. H. Schunk (Eds.), Handbook of self-regulation of learning and performance (pp. 15-32). New York, NY: Routledge.

Winne, P. H., \& Baker, R. S. J. D. (2013). The potentials of educational data mining for researching metacognition, motivation and self-regulated learning. Journal of Educational Data Mining, 5(1), $1-8$.

Winne, P. H., \& Hadwin, A. F. (1998). Studying as self-regulated engagement in learning. In D. Hacker, J. Dunlosky, \& A. Graesser (Eds.), Metacognition in educational theory and practice (pp. 277-304). Hillsdale, NJ: Erlbaum.

Zimmerman, B. J. (2000). Attaining self-regulation: A social cognitive perspective. In M. Boekaerts, P. R. Pintrich, \& M. Zeidner (Eds.), Handbook of self-regulation (pp. 13-40). San Diego, CA: Academic Press. doi: 10.1016/b978-012109890-2/50031-7

Zimmerman, B. J. (2013). From cognitive modeling to self-regulation: A social cognitive career path. Educational Psychologist, 48(3), 135-147. doi: 10.1080/00461520.2013.794676 
Zimmerman, B. J., \& Moylan, A. R. (2009). Self-regulation: Where metacognition and motivation intersect. In D. J. Hacker, J. Dunlosky, \& A. C. Graesser (Eds.), Handbook of metacognition in education (pp. 299-315). New York, NY: Routledge.

Athabasca

University

(c) 